Original Article

\title{
Behavior of the total antioxidant status in a group of subjects with metabolic syndrome
}

\author{
Eugenia Hopps *, Baldassare Canino, Maria Montana, Rosalia Lo Presti, Maurizio R. Averna, \\ Gregorio Caimi
}

Dipartimento Biomedico di Medicina Interna e Specialistica, Università di Palermo, Via del vespro 129, 90100 Palermo, Italy

\section{A R T I C L E I N F O}

\section{Keywords:}

Total antioxidant status

Metabolic syndrome

Diabetes mellitus

\begin{abstract}
A B S T R A C T
Aims: Our purpose was to examine the total antioxidant status (TAS) in subjects with metabolic syndrome (MS) subdivided according to the presence or not of diabetes mellitus.

Methods: We enrolled 106 subjects ( 45 women, 61 men) with MS subsequently subdivided in diabetics ( 14 women, 29 men) and nondiabetics ( 31 women, 29 men). TAS was obtained using an Assay kit which relies on the ability of plasma antioxidant substances to inhibit the oxidation of 2,2'-azino-bis(3ethylbenzthiazoline sulfonic acid) to the radical $\mathrm{ABTS}^{\bullet}+$.

Results: In the group of MS subjects a significant decrease in TAS $(p<0.05)$ in comparison with normal controls was evident. This difference was present between normal subjects and nondiabetic subjects with MS $(p<0.001)$ but not between normal and diabetic subjects with MS. Examining the linear regression among TAS, age, anthropometric profile, blood pressure values and glycometabolic pattern, conflicting data were found.

Conclusions: Although we know that TAS includes several enzymatic and non enzymatic antioxidants, we retain that the difference observed in the two subgroups of subjects with MS must be looked in particular into two pathophysiological aspects regarding bilirubin and uric acid.
\end{abstract}

(c) 2014 Diabetes India. Published by Elsevier Ltd. All rights reserved.

\section{Introduction}

Up to now several antioxidants, including retinol, retinyl esters, carotenoids ( $\beta$-carotene, $\alpha$-carotene, $\beta$-cryptoxanthin, lycopene and zeaxanthin/lutein), vitamin $\mathrm{E}$ and vitamin $\mathrm{C}$, have been examined in patients with metabolic syndrome (MS) [1,2] while previously observational studies have regarded the levels of serum carotenoids in MS [3] and in type 2 diabetes mellitus (DM) [4]. Conversely, many research have looked at the effects of long-term antioxidant supplementation in adults with risk of MS [5] and in type 2 diabetic subjects [6] with contrasting results.

The antioxidant defence includes the hydrosoluble antioxidants such as uric acid, vitamin $C$, total proteins and albumin, the liposoluble antioxidants, as bilirubin and vitamin $\mathrm{E}$, and the enzymatic antioxidants such as superoxide dismutase, catalase, glutathione peroxidase. In the clinical practice the antioxidant status may be altogether investigated as total antioxidant capacity (TAC), ferric reducing ability of plasma (FRAP), total antioxidant activity (TAA), total radical-trapping antioxidant parameter (TRAP) and total antioxidant status (TAS).

\footnotetext{
* Corresponding author. Tel.: +39 091 6554406; fax: +39 0916554535 .
}

We know that MS represents a multifactorial status characterized by different combinations of three or more of the following clinical conditions: diabetes mellitus, arterial hypertension, dyslipidemia and visceral obesity, and in this syndrome as well as in its principal features the behavior of total antioxidant status has been examined. In many papers [7-12] that have regarded MS, this parameter has been found reduced. In the paper of Sebekova et al. [13] regarding the association of MS risk factors in health omnivores (traditional western mixed diet) and vegetarians, FRAP was different between the two groups, after the subdivision according to the risk factor. In fact, while in omnivores the trend of antioxidant status changed in relation to the number of risk factors, although not significantly, that did not happen in the vegetarian group.

There are more information about antioxidant status in the principal components of MS. In morbid obesity [14] and in overweight subjects without MS [12] no statistical difference was observed in total antioxidant status. In type 2 DM the antioxidant status resulted reduced in some papers [15-17] although Savu et al. [18] observed its increase in comparison with control subjects. These authors [18] in subjects with uncomplicated type 2 DM also found a significant increase in plasma concentrations of uric acid and copper and in ceruloplasmin activity. As it is known, copper 
is a cofactor of superoxide dismutase, which acts as an antioxidant enzyme, but at the same time it may exert pro-oxidative effects, as well as ceruloplasmin. The antioxidant status significantly improved in morbidly obeses with type 2 DM undergoing bariatric surgery [19]. This parameter, according to some authors, clearly distinguished diabetic subjects with and without proteinuria even if others did not observe this distinction [20]. In type 2 diabetic subjects the plasma total antioxidant status was also related to the glycometabolic control and to vascular complications [15]. Lapolla et al. [21] noted significantly lower levels of TRAP in type 2 diabetics with peripheral artery disease (PAD) in comparison with type 2 diabetics without PAD. In arterial hypertension some authors have described a TAS decrease [22-24]; this finding has been noted also in subjects with prehypertension [22]. In hypertensives with metabolic syndrome TAS was reduced in comparison with hypertensives without MS [25]. The total antioxidant status was also negatively correlated with insulin resistance in hypercholesterolemic patients [26] while the data regarding this parameter after lipid-lowering therapy seem to be controversial; in fact, while bezafibrate reduces the plasma total antioxidant activity [27] and atorvastatin rises this parameter [28], simvastatin seems to act on this parameter with different effects $[29,30]$.

Considering this preamble our aim was to examine the TAS in MS subjects according to the presence or not of DM.

\section{Subjects and methods}

We enrolled 106 consecutive subjects with MS (61 men and 45 women), defined following the International Diabetes Federation (IDF) criteria [31]. Subsequently MS subjects were subdivided in diabetics ( 29 men and 14 women) and in nondiabetics ( 32 men and 31 women).

In the entire group of MS subjects mean age was $53.5 \pm 8.9$ years, BMI was $32.21 \pm 4.53$, waist circumference was $106.7 \pm 11.2 \mathrm{~cm}$, SBP and DBP were respectively $132.1 \pm 16.3$ and $81.2 \pm 9.9 \mathrm{mmHg}$, fasting blood glucose was $114.3 \pm 44.3 \mathrm{mg} / \mathrm{dl}$, total cholesterol was $213.9 \pm 53.0 \mathrm{mg} / \mathrm{dl}$, HDL-chol was $40.4 \pm 10.8 \mathrm{mg} / \mathrm{dl}$, LDL-chol was $133.2 \pm 46.5 \mathrm{mg} / \mathrm{dl}$ and triglycerides were $220.2 \pm 147.8 \mathrm{mg} / \mathrm{dl}$. In the subgroup of diabetic MS subjects mean age was $58.9 \pm 6.0$ years, BMI was $33.2 \pm 5.0$, waist circumference was $114.4 \pm 11.7 \mathrm{~cm}$, SBP and DBP were respectively $136.0 \pm 20.5$ and $79.6 \pm 11.4 \mathrm{mmHg}$, fasting blood glucose was $147.5 \pm 54.2 \mathrm{mg} /$ $\mathrm{dl}$, total cholesterol was $193.1 \pm 53.1 \mathrm{mg} / \mathrm{dl}$, HDL-chol was $41.4 \pm 12.8 \mathrm{mg} / \mathrm{dl}$, LDL-chol was $112.8 \pm 39.7 \mathrm{mg} / \mathrm{dl}$ and triglycerides were $204.2 \pm 150.9 \mathrm{mg} / \mathrm{dl}$. In the subgroup of nondiabetic MS subjects mean age was $49.7 \pm 8.6$ years, BMI was $31.5 \pm 4.2$, waist circumference was $102.8 \pm 8.8 \mathrm{~cm}$, SBP and DBP were respectively $130.0 \pm 13.3$ and $82.2 \pm 8.9 \mathrm{mmHg}$, fasting blood glucose was $92.2 \pm 10.3 \mathrm{mg} / \mathrm{dl}$, total cholesterol was $228.0 \pm 48.3 \mathrm{mg} / \mathrm{dl}$, HDLchol was $39.7 \pm 9.3 \mathrm{mg} / \mathrm{dl}$, LDL-chol was $147.9 \pm 45.8 \mathrm{mg} / \mathrm{dl}$ and triglycerides were $231.0 \pm 145.9 \mathrm{mg} / \mathrm{dl}$.

The study was approved by Ethical Commettee and each subject gave informed consent.

Blood samples were collected by venous puncture from the antecubital vein of each subject and immediately transferred to glass tube anticoagulated with EDTA-K3 to evaluate TAS. Total antioxidant status was obtained using an Assay kit (Calbiochem, La Jolla, USA) which relies on the ability of plasma antioxidant substances to inhibit the oxidation of 2,2'-azino-bis(3-ethylbenzthiazoline sulfonic acid) (ABTS) to the radical cation ABTS $^{\bullet+}$ by a peroxidase [32]. The radical concentration was measured by spectrophotometry.

The same parameter was also examined in a group of 54 normal subjects (35 men and 19 women, mean age $41.3 \pm 7.4$ years) recruited from the hospital staff members.

The values were expressed as means \pm s.d.; the differences between subjects with metabolic syndrome, diabetics and nondia- betics, and normal controls were evaluated using Student's $t$ test for unpaired data; the correlations were performed employing the linear regression test. The null hypothesis was rejected for $p$ values less than 0.05 .

\section{Results}

The obtained data show that, in comparison with normal subjects, in the whole group of MS subjects was evident a decrease in TAS $(N=0.986 \pm 0.238$; MS $=0.882 \pm 0.223, p<0.05)$. This datum was also present between normal subjects and nondiabetic subjects with MS $(N=0.986 \pm 0.238$; NDMS $=0.809 \pm 0.211, p<0.001)$ but not between normal subjects and diabetic subjects with MS $(N=0.986 \pm 0.238 ; \quad$ DMS $=0.987 \pm 0.199)$. The total antioxidant status was also significantly different $(p<0.001)$ between diabetic and nondiabetic MS subjects. Examining the linear regression between TAS, age, anthropometric profile, blood pressure values and glycometabolic pattern, we found in the whole group of MS subjects a positive correlation between TAS and age $(r=0.251$, $p<0.01)$, TAS and waist circumference $(r=0.386, p<0.001)$, TAS and fasting glucose level $(r=0.250, p<0.05)$, and also between TAS and triglycerides $(r=0.238, p<0.05)$. In the subgroup of nondiabetic MS subjects we noted a positive correlation between TAS and waist circumference $(r=0.310, p<0.05)$ and a negative correlation between TAS and HDL-cholesterol $(r=-0.290, p<0.05)$, while in the subgroup of diabetic subjects with MS we observed a positive correlation between TAS and diastolic blood pressure $(r=0.418$, $p<0.05)$ and between TAS and total cholesterol $(r=0.388, p<0.05)$, TAS and LDL-cholesterol $(r=0.400, p<0.05)$ and also between TAS and triglycerides $(r=0.408, p<0.01)$.

\section{Discussion}

The reduction of total antioxidant status observed in the entire group of MS subjects confirms almost quite what has been observed previously in MS and also in its principal components, although the datum that deserves to be underlined regards the different behavior observed in diabetic and nondiabetic subjects with MS. Even if in diabetes mellitus the observations regarding the TAS are not univocal [15-18], we think that this distinction needs specific considerations. We know that the evaluation of total antioxidant status includes enzymatic and non-enzymatic antioxidants and it is not possible to exclude that the difference observed in these two subgroups of MS subjects must be looked especially into two pathophysiological aspects concerning the levels of bilirubin and uric acid.

Some data, in fact, have underlined the protective role played by bilirubin in metabolic syndrome [33,34], but we do not dispose of its values in the two subgroups. As it is known, bilirubin acts as antioxidant irrespective of whether it is unconjugated, conjugated or albumin bound and at the same time we know that in diabetes mellitus is present an erythrocyte mechanical fragility, significantly correlated to fasting plasma glucose and to lipid peroxidation [35], that, inducing intravascular hemolysis, theoretically may induce a bilirubin increase.

The other pathophysiological aspect regards the role of uric acid in metabolic syndrome. A relationship between hyperuricemia and various MS components (hypertension, obesity, diabetes mellitus) has been demonstrated [36-39] and serum uric acid levels seem to be clearly associated with the prevalence of MS [36] and the incidence of DM [40]. In addition, in type 2 diabetic subjects hyperuricemia is correlated with the vascular complications, such as retinopathy, cerebrovascular and coronary artery diseases, and nephropathy [41].

In the last years a paradoxal role of uric acid has been hypothesized as it could act as an antioxidant in plasma and 
extracellular environment and as a pro-oxidant within the cells [40,42]; it is not possible to exclude that MS subjects with type 2 diabetes mellitus were hyperuricemic but we know the serum uric acid levels of a small group of MS subjects (data not shown).

The study of the linear regression among TAS, age, anthropometric profile, blood pressure values and glycometabolic pattern seems to be controversial and then some statistical correlation may be fortuitous and biologically inexplicable. Although in the entire group of MS subjects we found a positive correlation between TAS and age, in Attica study [22] this statistical correlation was negative. Regarding the positive correlation observed among TAS, total cholesterol, LDL-cholesterol and triglycerides in the subgroup of diabetics with MS, and the negative correlation between TAS and HDL-cholesterol in nondiabetics with MS, we have few information; however, in Attica study [22] no significant correlation was observed between TAS and plasma lipids, and other authors noted only a negative correlation between TAS and total cholesterol level. The positive correlation among TAS, waist circumference, blood glucose levels, and diastolic blood pressure seems to be occasional. At this regard, in the paper of Demircan [8] TAS was negatively correlated to the blood pressure values; no significant correlation was whereas found between TAS and blood glucose levels in the Attica study [22] while a negative correlation between these two parameters was reported by other authors [15].

Two are the consideration that can be drawn from these results concerning the group of MS subjects subdivided according to the presence or not of diabetes mellitus. The first regards the datum that in the subgroup of diabetics with MS the total antioxidant status was similar to that found in normal controls; the second regards the probable ineffectiveness of any specific oral supplementation in these subjects.

At the same time in order to confirm the alteration of oxidative status accompanying the MS, in the entire group of MS $(r=0.268$, $p<0.055)$ and in the subgroup of MS diabetics $(r=0.375$, $p<0.0131$ ) we found a significant and positive correlation between TAS and lipid peroxidation, expressed as thiobarbituric acid reactive substances (TBARS).

The evaluation of TAS may be an useful marker in the monitoring of MS, considering that its trend may be influenced by the use of several drugs, such as oral hypoglycemic agents [43], lipid lowering drugs [28,29] and antihypertensive agents [44], able to influence this parameter of oxidative status.

This research, confirming the literature data regarding the behavior of TAS in subjects with MS, clearly underlines how its trend is dependent on the presence of DM and it is possible to suppose that this datum could be influenced by non-enzymatic factors not evaluated in this preliminary study. At the same time, this finding needs further investigation thus, up to now, many research have regarded the use of the antioxidant supplementation in type 2 diabetic subjects with conflicting results. In fact, several studies have demonstrated that in diabetic subjects vitamin E supplementation improves blood glucose levels [45], and oxidative status parameters [46]. As well as the combination of vitamin $E$ and $C$ reduced $\mathrm{HbA} 1 \mathrm{c}$ and increased the activity of some antioxidant enzymes [47]. In diabetic obese subjects, the supplementation with vitamin $\mathrm{E}$ and omega-3 fatty acids, besides increasing total antioxidant capacity and antioxidant enzymes activity, reduced lipid peroxidation and protein carbonylation [48]. Also the oral administration of $\alpha$-lipoic acid reduces lipid peroxidation and improves glycometabolic control [49]. On the other hand, the association of vitamin E and A had no beneficial effects on cardiovascular events and mortality in type 2 diabetics [50].

\section{Conflict of interest}

No conflict of interest

\section{References}

[1] Beydoun MA, Canas JA, Beydoun HA, Chen X, Shroff MR, Zonderman A. Serum antioxidant concentrations and metabolic syndrome are associated among U.S. adolescents in recent national surveys. J Nutr 2012;142(9):1693-704.

[2] Suzuki K, Ito Y, Inoue T, Hamajima N. Inverse association of serum carotenoids with prevalence of metabolic syndrome among Japanese. Clin Nutr 2011;30(3):369-75

[3] Coyne T, Ibiebele TI, Baade PD, McClintock C, Shaw J. Metabolic syndrome and serum carotenoids: findings of a cross-sectional study in Queensland, Australia. Br J Nutr 2009;102(11):1668-77.

[4] Hozawa A, Jacobs Jr DR, Steffes MW, Gross MD, Steffen LM, Lee DH. Associations of serum carotenoid concentrations with the development of diabetes and with insulin concentration: interaction with smoking: the Coronary Artery Risk Development in Young Adults (CARDIA) Study. Am J Epidemiol 2006;163(10):929-37.

[5] Czernichow S, Vergnaud AC, Galan P, Arnaudm J, Favier A, Faure H, et al. Effects of long-term antioxidant supplementation and association of serum antioxidant concentrations with risk of metabolic syndrome in adults. Am J Clin Nutr 2009;90(2):329-35.

[6] Kataja-Tuomola M, Sundell JR, Männistö S, Mannisto S, Albanes D, Virtamo JR Effect of alpha-tocopherol and beta-carotene supplementation on the incidence of type 2 diabetes. Diabetologia 2008;51(1):47-53.

[7] Demirbag R, Yilmaz R, Gur M, Celik H, Guzel S, Selek S, et al. DNA damage in metabolic syndrome and its association with antioxidative and oxidative measurements. Int J Clin Pract 2006;60(10):1187-93.

[8] Demircan N, Gurel A, Armutcu F, Unalak M, Aktunc E, Atmaca H. The evaluation of serum cystatin $C$, malondialdehyde, and total antioxidant status in patients with metabolic syndrome. Med Sci Monit 2008;14(2):CR97-101.

[9] Skalicky J, Muzakova V, Kandar R, Meloun M, Rousar T, Palicka V. Evaluation of oxidative stress and inflammation in obese adults with metabolic syndrome Clin Chem Lab Med 2008;46(4):499-505.

[10] Sánchez-Rodríguez MA, Martínez-Cruz M, Correa-Muñoz E, Mendoza-Nunez VM. Relationship between metabolic syndrome components and oxidative stress in elderly community-dwelling Mexicans. Ann Nutr Metab 2010;56(4):302-7.

[11] Karamouzis I, Pervanidou P, Berardelli R, Iliadis S, Papassotiriou I, Karamouzis $\mathrm{M}$, et al. Enhanced oxidative stress and platelet activation combined with reduced antioxidant capacity in obese prepubertal and adolescent girls with full or partial metabolic syndrome. Horm Metab Res 2011;43(9):607-13.

[12] Venturini D, Simão AN, Scripes NA, Bahls LD, Melo PA, Belinetti FM, et al Evaluation of oxidative stress in overweight subjects with or without metabolic syndrome. Obesity (Silver Spring) 2012;20(12):2361-6.

[13] Sebeková K, Boor P, Valachovicová M, Blazicek P, Parrak V, Babinska K, et al. Association of metabolic syndrome risk factors with selected markers of oxidative status and microinflammation in healthy omnivores and vegetarians. Mol Nutr Food Res 2006;50(9):858-68.

[14] Mancini A, Leone E, Festa R, Grande G, Di Donna V, De Marinis L, et al. Evaluation of antioxidant systems (coenzyme Q10 and total antioxidant capacity) in morbid obesity before and after biliopancreatic diversion. Metabolism 2008;57(10):1384-9.

[15] Komosińska-Vassev K, Olczyk K, Olczyk P, Winsz-Szczotka K. Effects of metabolic control and vascular complications on indices of oxidative stress in type 2 diabetic patients. Diabetes Res Clin Pract 2005;68(3):207-16.

[16] Gul A, Rahman MA. Antioxidant status in diabetic and non-diabetic senile patients, with cataract or cardiovascular complications. Saudi Med ] 2008;29(2):179-84

[17] Odum EP, Ejilemele AA, Wakwe VC. Antioxidant status of type 2 diabetic patients in Port Harcourt, Nigeria. Niger J Clin Pract 2012;15(1):55-8

[18] Savu O, Ionescu-Tirgoviste C, Atanasiu V, Garman L, Papacocea R, Stoian I. Increase in total antioxidant capacity of plasma despite high levels of oxidative stress in uncomplicated type 2 diabetes mellitus. J Int Med Res 2012;40(2):709-16.

[19] Prior SL, Bain SC, Stephens JW, Alam I, Baxter JN. Total antioxidant status before and after bariatric surgery for type 2 diabetes mellitus. Metabolism 2009;58(9):1366.

[20] Piarulli F, Sartore G, Ceriello A, Ragazzi E, Reitano R, Nollino L, et al. Relationship between glyco-oxidation, antioxidant status and microalbuminuria in type 2 diabetic patients. Diabetologia 2009;52(7):1419-25.

[21] Lapolla A, Piarulli F, Sartore G, Ceriello A, Ragazi E, Reitano R, et al. Advanced glycation end products and antioxidant status in type 2 diabetic patients with and without peripheral artery disease. Diab Care 2007;30:670-6.

[22] Chrysohoou C, Panagiotakos DB, Pitsavos C, Skoumas J, Economou M, Papadimitriou L, et al. The association between pre-hypertension status and oxidative stress markers related to atherosclerotic disease: the ATTICA study. Atherosclerosis 2007;192(1):169-76.

[23] Kuklinska AM, Mroczko B, Musial WJ, Sawicki R, Kozieradzka A, Waszkiewicz $\mathrm{E}$, et al. High-sensitivity C-reactive protein and total antioxidant status in patients with essential arterial hypertension and dyslipidemia. Adv Med Sci 2009;54(2):225-32 
[24] Subash P, Premagurumurthy K, Sarasabharathi A, Cherian KM. Total antioxidant status and oxidative DNA damage in a South Indian population of essential hypertensives. J Hum Hypertens 2010;24(7):475-82.

[25] Shin MJ, Shim E, Kang B, Park S, Lee SH, Shim CY, et al. Increased inflammation, reduced plasma phospholipid eicosapentaenoic acid and reduced antioxidant potential of treated hypertensive patients with metabolic syndrome. Yonsei Med J 2009;50(6):757-63.

[26] Shin MJ, Park E, Lee JH, Chung N. Relationship between insulin resistance and lipid peroxidation and antioxidant vitamins in hypercholesterolemic patients. Ann Nutr Metab 2006;50(2):115-20.

[27] Grodzińska L, Jachym R, Sławiński M, Robak J. Influence of bezafibrate on total antioxidant activity of serum and deformability of blood cells in hypercholesterolaemic patients. Pol J Pharmacol 1998;50(4-5):361-4.

[28] Orem C, Orem A, Uydu HA, Celik S, Erdol C, Kural BV. The effects of lipidlowering therapy on low-density lipoprotein auto-antibodies: relationship with low-density lipoprotein oxidation and plasma total antioxidant status. Coron Artery Dis 2002;13(1):65-71.

[29] Molcányiová A, Stancáková A, Javorský M, Tkac I. Beneficial effect of simvastatin treatment on LDL oxidation and antioxidant protection is more pronounced in combined hyperlipidemia than in hypercholesterolemia. Pharmacol Res 2006;54(3):203-7.

[30] Shin MJ, Chung N, Lee JH, Jang Y, Park E, Jeon KI, et al. Effects of simvastatin on plasma antioxidant status and vitamins in hypercholesterolemic patients. Int J Cardiol 2007;118(2):173-7.

[31] Alberti KG, Zimmet P, Shaw J. Metabolic Syndrome-a new world-wide definition. A Consensus Statement from the International Diabetes Federation. Diabetic Med 2006;23:469-80.

[32] Miller NJ, Rice-Evans C, Davies MJ, Gopinathan V, Milner A. A novel method for measuring antioxidant capacity and its application to monitoring the antioxidant status in premature neonates. Clin Sci 1993;89:407-12.

[33] Giral P, Ratziu V, Couvert P, Carrie A, Kontush A, Girerd X, et al. Plasma bilirubin and gamma-glutamyltransferase activity are inversely related in dyslipidemic patients with metabolic syndrome: relevance to oxidative stress. Atherosclerosis 2010;210(2):607-13.

[34] Vitek L. The role of bilirubin in diabetes, metabolic syndrome, and cardiovascular diseases. Front Pharmacol 2012;3:55.

[35] Lippi G, Mercadanti M, Aloe R, Targher G. Erythrocyte mechanical fragility is increased in patients with type 2 diabetes. Eur J Intern Med 2012;23(2):150-3.

[36] Chang CH, Chen YM, Chuang YW, Liao SC, Lin CS, Tang YJ, et al. Relationship between hyperuricemia (HUC) and metabolic syndrome (MS) in institutionalized elderly men. Arch Gerontol Geriatr 2009;49(Suppl. 2):S46-9.

[37] Hara S, Tsuji H, Ohmoto Y, Amakawa K, Hsieh SD, Arase Y, et al. High serum uric acid level and low urine $\mathrm{pH}$ as predictors of metabolic syndrome: retrospective cohort study in a Japanese urban population. Metabolism 2012;61(2):281-8.

[38] Chiou WK, Huang DH, Wang MH, Lee YJ, Lin JD. Significance and association of serum uric acid (UA) levels with components of metabolic syndrome (MS) in the elderly. Arch Gerontol Greiatr 2012;55:724-8.

[39] Osgood K, Krakoff J, Thearle M. Serum uric acid predicts both current and future components of the metabolic syndrome. Metab Syndr Relat Disord 2013;11:157-62.

[40] Jia Z, Zhang X, Kang S, Wu Y. Serum uric acid levels and incidence of impaired fasting glucose and type 2 diabetes mellitus: a meta-analysis of cohort studies. Diab Res Clin Pract 2013;101:88-96.

[41] Ito H, Abe M, Mifune M, Oshikiri K, Antoku S, Takeuci Y, et al. Hyperuricemia is independently associated with coronaty heart disease and renal dysfunction in patients with type 2 diabetes mellitus. PLoS ONE 2011;6:e27817.

[42] Sautin YY, Johnson RJ. Uric acid: the oxidant-antioxidant paradox. Nucleosides Nucleotides Nucleic Acids 2008;27(6):608-19.

[43] Abdulkadir AA, Thanoon IA. Comparative effects of glibenclamide and metformin on C-reactive protein and oxidant/antioxidant status in patients with Type II diabetes mellitus. Sultan Qaboos Univ Med J 2012;12(1):55-61.

[44] Krouf D, Bouchenak M, Mohammedi B, Cherrad A, Belleville JL, Prost JL. Changes in serum lipids and antioxidant status in west Algerian patients with essential hypertension treated with acebutolol compared to healthy subjects. Med Sci Monit 2003;9(8):PI109-15.

[45] Jain AB, Jain VA. Vitamin E, its beneficial role in diabetes mellitus (DM) and its complications. J Clin Diagn Res 2012;6:1624-8.

[46] Shinde SN, Dhadke VN, Suryakar AN. Evaluation of oxidative stress in type 2 diabetes mellitus and follow-up along with vitamin E supplementation. Indian J Clin Biochem 2011;26:74-7.

[47] Rafighi Z, Shiva A, Arab S, Mohd Yousof R. Association of dietary vitamin C and E intake and antioxidant enzyme in type 2 diabetes mellitus patients. Glob J Health Sci 2013;5:183-7.

[48] Sarbolouki SH, Djalali M, Dorosty AR, Djazayery SA, Eshraghian MR, Ebadi SAR, et al. Effects of EPA and vitamin E on serum enzymatic antioxidants and peroxidation indices in patients with type II diabetes mellitus. Iran J Public Health 2010;39:82-91.

[49] Porasuphatana S, Suddee S, Nartnampong A, Konsil J, Harnwong B, Samtaweeksuk A. Glycemic and oxidative status of patients with type 2 diabetes mellitus following oral administration of alpha-lipoic acid: a randomized double-blind placebo-controlled study. Asia Pac J Clin Nutr 2012;21:12-21.

[50] Kataja-Tuomola MK, Kontto JP, Mannisto S, Albanes D, Virtamo JR. Effect of alpha-tocopherol and beta-carotene supplementation on macrovascular complications and total mortality from diabetes: results of the ATBC Study. Ann Med 2010;42:178-86. 